\title{
Trinta anos de pesquisa em remuneração executiva e retorno para o acionista
}

\section{Resumo}

Objetivo: Investigamos a produção bibliográfica sobre remuneração de executivos nos cenários brasileiro e internacional, a fim de formar uma base teórica para o desenvolvimento de pesquisas empíricas que envolvam o tema. Elegemos a pesquisa de Jensen e Murphy (1990) como marco inicial das discussões sobre a temática. Método: Trata-se de uma revisão de literatura. A pesquisa foi elaborada com buscas de palavras-chave, por meio da ferramenta EndNote ${ }^{\text {me }}$ e o Scientific Periodicals Electronic Library (SPELL), mantido no Brasil pela Associação Nacional de Pós Graduação e Pesquisa em Administração (Anpad) sendo: i) Executive Compensation; ii) CEO Compensation; iii) Company performance combinada com a palavra Compensation e os termos correspondentes em português na base brasileira.

Resultados: Os principais estudos publicados concentram-se nos cenários norte-americano e britânico, com destaque para os professores Michael C. Jensen (Harvard University), Kevin M. Murphy (University of Southern California) e Martin J. Conyon (University of Pennsylvania). Jensen participou do estudo que marcou a discussão do problema de agência (Jensen \& Meckling, 1976). Murphy desenvolve pesquisas sobre a temática a partir dos anos 1980, no cenário norte-americano, período que também marca o início dos estudos de Conyon, porém, no cenário britânico. Os três autores são referência no tema e desenvolvem estudos em outros cenários econômicos, tais como Canadá, Alemanha e, mais recentemente, China.

Contribuições: Os achados aqui trazidos contribuem para o desenvolvimento de novas pesquisas, de caráter empírico, principalmente em países em que a temática se encontra em desenvolvimento ou em regiões em que surja o interesse pelo assunto, com o incremento destas variáveis para contribuir com o entendimento do problema de agência.

Palavras chave: Remuneração executiva; Retorno para o acionista Bibliometria.
Juliano Augusto Orsi de Araujo Doutorando em Contabilidade pela Universidade de São Paulo (Fearp/ USP). Contato: Rua Manoel de Toledo, 263, subsolo, Centro, Atibaia (SP), CEP.: 12.940-213.

E-mail:julianoorsi@usp.br

Maísa de Souza Ribeiro Doutora em Controladoria e Contabilidade pela Universidade de São Paulo (USP) e Professora Titular na Universidade de São Paulo (Fearp/USP). Contato: Avenida dos Bandeirantes, 3900, sala 14C, Monte Alegre, Ribeirão Preto (SP), CEP.: 14040-900

E-mail: maisorib@usp.br 


\section{Introdução}

Neste artigo, investigamos a produção bibliográfica sobre remuneração de executivos e o retorno ao acionista nos cenários brasileiro e internacional, a fim de formar uma base teórica para o desenvolvimento de pesquisas empíricas que envolvam o tema. As pesquisas sobre remuneração executiva e sua implicação prática sempre são questionadas quando da existência de crises e/ou problemas concentrados no meio empresarial. Observa-se o episódio dos "bônus milionários" e mais recentemente, em 2009, quando os Estados Unidos ainda estavam enredados pela crise mundial e o congresso americano voltou suas atenções para identificar o responsável, que culminou com a eleição da "cultura dos bônus de Wall Street". Também há de se observar os casos Enron / WorldCom e a crise subprime 2007 (Krauter \& Souza, 2013).

A relação existente entre executivos e acionistas é percebida por Jensen e Meckling (1976) quando da divulgação da teoria da Agência, tal que o principal (acionista), detentor do capital, contrata o agente (executivo) que possui a expertise de gerir e tomar decisões acerca de um negócio, a seu favor. Entretanto, se houver a maximização da utilidade pessoal de cada um, existem razões para crer que o agente nem sempre agirá conforme o principal espera, fato este gerador do conflito de agência. Araujo, Parisi, Silva e Nakamura (2014) afirmam que a distinção das pessoas do proprietário e do gestor é uma tendência natural da economia globalizada. Para os autores, o acirramento do mercado faz com que as companhias busquem os melhores profissionais para o exercício da função de condução da empresa e tomada de decisões.

Os estudos iniciais foram desenvolvidos no cenário norte-americano, com os trabalhos de Murphy (1985); Jensen e Murphy (1990); Leonard (1990); Garen (1994); Miller (1995); Murphy (1998); Abowd e Kaplan (1999); Pukthuanthong, Talmor e Wallace (2004), e no cenário britânico, com as pesquisas de McKnight (1996); Conyon (1997) e Conyon e Sadler (2001). Há uma extensão de estudos em outros países da Europa como Alemanha (Conyon \& Schwalbach, 2000; Elston \& Goldberg, 2003), França (Alcouffe \& Alcouffe, 2000; El Akremi, Roussel \& Trepo, 2001), Itália (Brunello, Graziani \& Parigi, 2001) e também na China (Firth, Tam \& Tang, 1999).

Baker, Jensen e Murphy (1988) afirmam que a teoria e a prática acerca dos contratos de remuneração parecem particularmente distantes e que não há o uso do que prevê a teoria quando do desenho destes contratos. Barkema e Gomez-Mejia (1998), Kato, Kim e Lee (2005) e Krauter e Souza (2013) defendem que os estudos devem ser expandidos e desenvolvidos, além do cenário norte-americano. Como observado por Kato, Kim e Lee (2005), houve uma explosão de estudos no cenário americano e poucos estudos em outros mercados, como na Ásia, África e Américas Central e do Sul.

Os principais estudos publicados concentram-se nos cenários norte-americano e britânico, com destaque para os professores Michael C. Jensen (Harvard University), Kevin M. Murphy (University of Southern California) e Martin J. Conyon (University of Pennsylvania). O professor Jensen participou do estudo que marcou a discussão do problema de agência (Jensen \& Meckling, 1976). Murphy desenvolve pesquisas sobre a temática a partir dos anos 1980, no cenário norte americano, período que também marca o início dos estudos do prof. Conyon, porém, no cenário britânico. Os três autores são referência no tema e, a partir deste destaque, desenvolvem estudos em outros cenários econômicos, tais como Canadá, Alemanha e, mais recentemente, China. Também desenvolvem a expertise para o desenvolvimento de pesquisas comparando os cenários entre si.

No Brasil, o interesse pela pesquisa nessa temática cresceu na última década e tem despertado o interesse de pesquisadores das áreas de Contabilidade, Administração, Economia e Finanças, para entender como o fenômeno da remuneração de executivos e o retorno aos acionistas se comportam no ambiente brasileiro. Beuren e Silva (2015) entendem que a maior transparência com a divulgação destas informações contribui para o fortalecimento do mercado de capitais em que são divulgadas. No entanto, os resultados encontrados em pesquisas nacionais e internacionais são contraditórios e, não, conclusivos.

Para Quevedo-Silva, Santos, Brandão e Vils (2016), o uso de técnicas bibliométricas é uma prática comum em pesquisas sociais aplicadas, com o auxílio no entendimento de novas temáticas e tendências acerca de pesquisas futuras. Araujo (2006) contribui afirmando que é a técnica que mede a produção e disseminação do conhecimento científico. 


\section{Revisão de Literatura}

Os estudos voltados a investigar a relação entre a remuneração executiva e o retorno para os acionistas derivam da pesquisa de Jensen e Meckling (1976), que, a partir de elementos da teoria da Agência, da teoria dos Direitos de Propriedade e da teoria de Finanças, desenvolveram a teoria de Estrutura de Propriedade da Firma. Os autores definiram os conceitos de custos de agência e sua natureza. Muitos estudos buscaram, ao longo do tempo, apresentar o estado da arte sobre a temática, que se estende por décadas e ainda inspira pesquisadores a debruçar-se nos estudos a fim de buscar resultados conclusivos.

\subsection{Estudos iniciais - Estados Unidos e Reino Unido}

Algumas obras clássicas, entre elas a de Copeland, Weston e Shastri (2007), apontam para o trabalho de Jensen e Murphy (1990) como a obra seminal acerca dos estudos empíricos que testaram as relações entre remuneração e retorno.

No entanto, Murphy (1985) já apresentava inquietação sobre a temática, pois até então os estudos que buscavam identificar relação entre remuneração e desempenho não conseguiam resultados significativos por meio de ferramentas estatísticas. Murphy (1985) afirma que os estudos até então desenvolvidos omitiram algumas variáveis importantes e sugere o uso das informações acerca do retorno para o acionista e o crescimento de vendas. Em seu trabalho, Murphy (1985) identificou forte relação positiva entre performance e remuneração de executivos e também de aumento de vendas e remuneração.

Os achados anteriores se alinham com o que Jensen e Murphy (1990) encontraram cinco anos mais tarde. Pesquisaram as remunerações publicadas na Forbes entre 1974 e 1986 e estimaram que a relação existente entre pagamento e performance para os executivos indicaram um crescimento na remuneração de US $\$ 3,25$ cada US $\$ 1.000,00$ de acréscimo na riqueza do acionista. Os autores acreditam que esta relação encontrada, embora estatisticamente significativa e positiva, é pequena dada a importância dos cargos nas companhias. Ainda sugeriram que o fator "demissão" não deveria se apresentar relevante por se tratar de uma situação que não representa um incentivo.

Rosen (1990) traçou uma primeira revisão dos achados empíricos sobre remuneração executiva. O autor sugere que o controle deve ser distribuído entre os executivos e que os executivos mais talentosos devem ser alocados em posições de maior relevância e tomada de decisão e em grandes companhias, pois esse efeito é notado em grandes volumes transacionados. O autor também afirma que os contratos devem prover incentivos aos gestores de modo a incentivá-los a alcançar os interesses dos acionistas.

Gibbons e Murphy (1992), provocados pelos estudos até então desenvolvidos que afirmavam que os executivos atuavam visando apenas à construção de uma carreira, desenvolveram estudo para atestar que contratos com incentivos fariam a diferença sobre a performance do CEO e, consequentemente, da companhia. Para tal, aplicaram aos modelos desenvolvidos por Fama (1980) e Holmström (1982) variáveis de incentivo observadas nos contratos. Assim, incrementaram o estudo investigando a relação entre a remuneração executiva e a performance das ações da companhia no mercado acionário. Os autores identificaram que, com um acréscimo de $10 \%$ à riqueza do acionista, aumenta em 1,7\% na remuneração executiva.

Conyon e Gregg (1994) também encontraram relação da remuneração com as vendas. Os autores estimaram modelo relacionando pagamento a diretores e retorno para os acionistas também durante os anos 1980. Em uma amostra de cerca de 170 empresas britânicas entre 1985 e 1990, os autores encontraram relação significativa entre remuneração e retorno aos acionistas, mas com elasticidade pequena. Em mais um estudo em que os autores se sentiram provocados pelo controverso pacote de benefícios oferecidos aos CEOs não condizentes com o desempenho econômico apresentados pelas companhias, Conyon e Leech (1994) levantaram dados de 294 empresas britânicas listadas entre os anos de 1983 e 1986. Os autores testaram a relação entre os maiores pagamentos a diretores e a performance das empresas, com variáveis de controle de tamanho e medidas de governança corporativa. Os autores identificaram relação 
positiva com uma elasticidade estimada bem pequena, o que entendem ser uma fraca relação. Reafirmam as evidências encontradas anteriormente e também encontraram relevância no montante de vendas, variável tida como explicativa pelos autores para o incremento na remuneração da diretoria.

Conyon, Gregg e Machin (1995) promovem uma revisão bibliográfica e uma discussão acerca das pesquisas sobre remuneração executiva e desempenho das companhias no Reino Unido. Apontam para os estudos de Jensen e Murphy (1990), Gregg, Machin e Szymanski (1993), Main (1992), Main e Johnston (1993), Conyon e Leech (1994), Conyon e Gregg (1994) e Conyon (1994) cujos autores encontraram pouca relação entre remuneração e desempenho. Entendem que a remuneração é inadequada e demonstram inquietação uma vez que há discrepância entre a remuneração de empregados em geral e os executivos de ponta das companhias britânicas. Sugerem reformas que permeiam a divulgação de informações e sistemas de incentivos apropriados, reorganização das práticas de governança e uma reforma nas normas que regulamentam estas remunerações.

Dial e Murphy (1995), em estudo de caso, investigaram o uso de incentivos à remuneração executiva para a criação de valor aos acionistas. As estratégias permearam a redução de tamanho das companhias e reestruturação. Em contrapartida, houve o pagamento de bônus aos executivos. Para os autores, $o$ mecanismo funcionou, uma vez que houve realização de ganhos aproximados de 4,5 bilhões de dólares, o que representou um crescimento de, aproximadamente, 553\% para o acionista. Os autores concluem que o alinhamento de incentivos aos executivos é fator determinante na geração de valor aos acionistas.

\subsection{Expansão para outros países europeus}

Existe também uma vertente que examinou a remuneração executiva à luz das práticas de governança executiva, aspectos legais e normativos locais e práticas contábeis adotadas. A exemplo, Conyon e Schwalbach (1997) examinaram o nível e estrutura das políticas de remuneração a executivos em 2846 companhias europeias nos anos 1990, comparando empresas austríacas, belgas, dinamarquesas, alemãs, irlandesas, italianas, holandesas, espanholas, suíças e britânicas. Identificaram que existem diferenças significativas entre os países daquele continente que são explicadas por particularidades dos cargos e pelo tamanho das companhias. Ao isolarem esses fatores, identificaram que características específicas dos países, como estruturas de governança corporativa, legislação e normas contábeis locais e modos distintos de mensuração da remuneração executiva, são relevantes na determinação da política de remuneração da companhia.

Conyon e Peck (1998) examinaram a relação entre diretoria executiva, comitês de remuneração e pagamento do alto escalão de companhias britânicas entre 1991 e 1994. Encontraram pequena relação entre o membro do comitê de remuneração atuar na companhia e a remuneração executiva, ou seja, quando os membros do comitê de remuneração também atuam na empresa, tendem a propor uma remuneração mais alta, se comparada quando o membro é externo à companhia. Os autores acreditam que quando há esta distância entre board e empresa, há uma tendência de maior alinhamento entre metas para executivos e interesses dos acionistas.

Clarke, Conyon e Peck (1998) sumarizaram, por meio de uma survey, dados de 342 companhias britânicas com foco em seus valores de governança corporativa e remuneração executiva. No entanto, difere-se das demais, pois se concentraram na visão dos executivos. Investigaram itens como accountability, prosperidade do negócio, divulgação de remuneração executiva e a relação com acionistas. Os autores encontraram evidências de que os presidentes das companhias estão alinhados com as regras e princípios estabelecidos pela legislação, agindo com cuidado nas questões de evidenciação contábil. Com isso, os decisores acreditam que se empenha muito esforço com questões regulatórias em detrimento a questões estratégicas que contribuiriam para a prosperidade do negócio. Ainda relatam que os executivos, em sua maioria, apontam para um aumento de exigências de divulgação de remuneração que, para eles, se trata de replicação de informação, já que a mídia especializada divulga esta informação. 
Conyon e Schwalbach (2000) também investigaram os fatores determinantes da remuneração executiva no Reino Unido e Alemanha durante o ano de 1994; identificaram diferenças nas regras de governança corporativa e características macroeconômicas entre os países; encontraram maior remuneração no Reino Unido e diferenças entre políticas de remuneração, tal que houve pagamento em opções no Reino Unido e, não, na Alemanha, fator este que contribuiu para uma maior remuneração naquele país. Em ambos os cenários, os autores identificaram forte relação entre remuneração executiva e a performance das empresas. Assim, encontramos um franco desenvolvimento das pesquisas também no cenário europeu no final dos anos 1990 e início dos anos 2000.

Murphy (1999) compilou em sua pesquisa trabalhos empíricos e teóricos sobre remuneração executiva publicados até 1998. O autor encontrou estudos com uso de variadas abordagens estatísticas em que constatou que variáveis, como tamanho da empresa, setor e país, influenciam os testes; encontrou trabalhos que exploraram as razões para a troca de executivos que, segundo ele, cresceu após a adoção da remuneração por ações ou opções; e sugere que os estudos sejam ampliados para verificar os efeitos em anos posteriores ao da remuneração baseada em ações.

\subsection{Comparações entre cenários}

Com o franco desenvolvimento de pesquisas na Europa e Estados Unidos, Conyon e Murphy (2000) firmaram parceria e documentam diferenças entre a remuneração de executivos nos Estados Unidos e no Reino Unido para o ano de 1997. Os autores controlaram variáveis, como tamanho, setor entre outras características de empresas e executivos. Identificaram que os CEOs norte-americanos percebem uma remuneração em caixa $45 \%$ superior à dos britânicos e $190 \%$ quando se fala de remuneração total. Os autores ainda identificaram que, nos Estados Unidos, o CEO percebe um acréscimo de 1,48\% em sua remuneração para cada unidade que aumenta a riqueza do acionista, ao passo que, no Reino Unido, este acréscimo é de apenas $0,25 \%$ para a mesma razão. Os autores concluem que esta diferença se dá, principalmente pela maior remuneração por meio de opções nos Estados Unidos, e se alongam em questões institucionais e culturais existentes entre os dois países.

Conyon e Sadler (2001) examinaram a relação entre remuneração e performance em companhias britânicas. Os autores desenvolveram o estudo à luz da teoria dos Jogos, que prediz que o plano de carreira gera incentivos aos executivos e pode explicar as variações de pagamentos de diretorias. A amostra de 532 executivos em 100 companhias britânicas revelou que há relação estatisticamente positiva entre a performance e a remuneração executiva por meio de opções.

Hall e Murphy (2003) apresentam o problema de se remunerar com opções de ações. Estes instrumentos patrimoniais são ofertados a muitas pessoas e se apresentou como uma forma muito comum de remuneração de executivos com o intuito de reduzir o problema de agência. Para os autores, esta forma de remuneração não é eficiente em atrair, reter ou motivar executivos. Além disso, os autores acreditam que os custos de emissão de opções superam os custos de agência identificados nos estudos.

Diante das discussões, há ainda trabalhos que sugerem mudanças na forma como as políticas de remuneração deveriam ser adotadas. Jensen, Murphy e Wruck (2004) desenvolveram estudo em que traçaram um panorama acerca dos estudos sobre remuneração executiva e suas implicações práticas no cenário norte-americano. $\mathrm{O}$ estudo compreende uma revisão de questões envolvendo o problema de agência entre gestores e acionistas, entre membros de conselhos e acionistas e uma discussão sobre o desenho de um pacote de remuneração alinhado com práticas de governança corporativa. Os autores sugerem que havia necessidade de mudanças, com foco no alinhamento dos pacotes de remuneração executiva, tornando-os claros ao mercado e como os autores definem como os executivos praticam o earnings-management game para atingir seus objetivos.

Conyon e He (2004) desenvolveram parceria que se iniciou com a pesquisa em que se concentraram em uma amostra de empresas em IPO para investigar a relação entre a remuneração de comitês, a remune- 
ração executiva e incentivos a eles. Encontraram uma relação entre a presença de grandes acionistas no comitê de remuneração e a baixa remuneração fixa e alta remuneração variável baseada em resultados. Nas empresas em que havia maiores compensações pagas aos membros dos comitês, havia uma associação com as maiores remunerações fixas e menores remunerações variáveis. Não encontraram evidências da participação de CEOs de outras companhias em comitês de remuneração e as políticas determinantes de remuneração.

\subsection{Os estudos se expandem pelo mundo}

Em meados dos anos 2000, pesquisadores demonstram interesse em replicar os testes em outros cenários econômicos. A exemplo, Kato, Kim e Lee (2005) apresentam o que intitulam de a primeira estimativa econométrica acerca da remuneração executiva e desempenho entre as empresas coreanas com demonstrações consolidadas ou não. Desenvolveram o estudo utilizando dados em painel contendo dados de remuneração e desempenho e se a empresa participa, ou não, de conglomerado econômico. Foram avaliadas 246 empresas entre os anos de 1998 e 2001. Contrariamente ao que os estudos anteriores apontavam para empresas orientais, os autores encontraram significância estatística entre remuneração executiva e performance dos preços das ações no mercado, comparadas aos mercados americano e japonês.

Também Funchal e Terra (2006), estudo tido como seminal no cenário brasileiro, examinaram os determinantes da remuneração dos executivos nas empresas de capital aberto latino-americanas com base em indicadores de desempenho e características de governança corporativa, incluindo características do conselho e da diretoria executiva, e sua estrutura de propriedade. Os autores sugerem que novos estudos não devem se concentrar apenas no alto escalão de diretores das companhias, mas expandir para executivos que não estão no topo. Mediram a remuneração apenas como os benefícios pecuniários diretos, ignorando outras formas de compensação tais como benefícios de aposentadoria, planos de participação, assistência médica, entre outros. Esses itens, contudo, frequentemente resultam em um relevante incremento anual na riqueza do executivo.

No ano seguinte, Camargos, Helal e Boas (2007) analisaram a relação existente entre o desempenho financeiro e a remuneração de executivos de empresas brasileiras de capital aberto que tem ADRs listados em bolsas norte-americanas. Concluíram que existe uma relação positiva e significante entre a remuneração e o desempenho financeiro. Sugerem desenvolver pesquisas com amostras maiores e em outros países, além do uso de dados em painel, analisando a interação das variáveis utilizadas nesta pesquisa ao longo do tempo.

Também no Brasil, Krauter e Souza (2013) investigaram a existência de relação entre a remuneração de executivos e o desempenho financeiro das empresas. Analisaram dados relativos a 2006, de $31 \mathrm{em}$ presas listadas na revista "As Melhores Empresas para Você Trabalhar", da revista Exame. Os resultados apontaram, por meio do teste não paramétrico de Mann-Whitney, que as empresas com alta pontuação no índice de benefício apresentam valores superiores nos indicadores financeiros de retorno sobre patrimônio líquido e margem das vendas. No entanto, o teste de correlação de Pearson não identificou relação linear significante entre remuneração de executivos e desempenho financeiro.

No final dos anos 2000 e início de 2010, alguns estudos voltam-se para a relação entre a remuneração e resultado, mas com uma variável de controle distinta até então: a participação de empresas de consultoria na elaboração da política de remuneração nas companhias. Conyon Peck e Sadler (2009) e Conyon (2011) investigaram a relação entre a existência de empresas especializadas em remuneração executiva e seus honorários profissionais. Essas empresas prestam serviços no sentido de orientar acerca de um pacote de remuneração para a alta diretoria. O primeiro concentrou-se nos cenários norte-americano e britânico, e o segundo apenas nos Estados Unidos. Os achados são muito parecidos, tal que encontraram uma remuneração maior em empresas que contratam consultorias. Também identificaram a presença de um pacote de remunerações baseadas em resultados em empresas que mantém relação com as consultorias e, por fim, identificaram que há uma pequena relação entre a contratação de consultorias e o surgimento de conflito de interesses, como relação à outras empresas e/ou clientes, leva a um pequeno aumento na remuneração executiva ou há um contrato de remuneração bastante específico. 
Na mesma linha, Murphy e Sandino (2009) também encontraram relação positiva entre a remuneração de empresas de consultoria e os níveis de pagamentos a executivos. Os autores desenvolveram estudo nos cenários norte-americano e canadense, afirmando que a remuneração executiva é maior em empresas que contratam serviços de consultoria para apoio na contratação e na elaboração de pacotes de remuneração a executivos. Os achados estão alinhados com Conyon, Peck e Sadler (2009) e Conyon (2011).

Murphy e Sandino (2012) também investigaram a relação existente entre a contratação de empresas de consultoria e a remuneração executiva. Segundo os autores, quando há a contratação de consultorias há influência no pagamento de salário dos cinco maiores executivos das companhias. Os autores encontraram relação, positiva na análise em que fizeram com 1.074 empresas. Nas empresas em que se mantem estas consultorias, os executivos percebem remuneração maior quando comparadas às empresas que não as contratam.

No entanto, os estudos entendem que não há uma relação de independência para que garanta uma prestação de serviços confiável. Os achados coincidem com a teoria, em que há relação entre a remuneração executiva e a remuneração paga às empresas de consultoria. Há forte relação entre contratação de outros serviços prestados pelos consultores e aumento na remuneração, e fraca relação entre a substituição de consultoria e aumento na remuneração executiva; sugerem explorar os determinantes desta relação, uma vez que companhias anseiam por profissionais de topo, que custam caro e que são contratados por consultorias igualmente caras.

Conyon, Core e Guay (2009) desenvolveram estudo em que compararam a remuneração executiva americana com a britânica, dado que os estudos anteriores não conseguiam entender altas remunerações com baixa rentabilidade no cenário americano e optaram por comparar os dois mercados, pois o Reino Unido não apresenta esta característica. Os autores encontraram uma remuneração muito maior nos Estados Unidos, quando comparado com o Reino Unido e procuraram então investigar se haveria um prêmio pelo risco ajustado. Ainda assim, baseados nesta premissa, os autores ainda encontraram uma remuneração muito maior e abriram a lacuna para investigar os determinantes que levam a remuneração norte-americana a ser tão maior que a britânica.

Conyon e Sadler (2010) investigaram os determinantes dos votos dos acionistas e sua relação com o pagamento de executivos. Tal pesquisa motivou-se pela abertura legal prevista no Reino Unido para que acionistas pudessem opinar acerca da remuneração executiva. Os autores encontraram que menos de 10 por cento dos acionistas deixaram de participar desta seção e entenderam que os acionistas estão preocupados em decidir e participar das definições acerca das políticas de remuneração; também apontam que quando há grandes salários nas companhias, há grande embate acerca da decisão sobre remuneração. Há evidências de que, em empresas em que a remuneração é menor, no passado, houve discussões entre acionistas acerca da remuneração executiva; também encontraram evidências de que nessas empresas houve um alinhamento entre gestores e acionistas no que tange à remuneração, e sinalizam que isso proporciona uma redução no problema de agência. Como estudos futuros, sugerem analisar cenários com crise e pós-crise e avaliar o comportamento do voto dos acionistas e a remuneração. Também recomendam verificar se há reação do mercado quando há grandes dissidências de voto; se esta situação aumenta a rotatividade de executivos; e se há queda no desempenho da empresa quando há intervenção direta dos acionistas na definição das políticas de remuneração executiva.

Jensen e Murphy (2010) debateram sobre o modo que as companhias americanas remuneram seus executivos, não se atentando para o montante, mas a forma. Segundo os autores, a política de remuneração é um dos principais fatores de sucesso em uma organização. Os autores criticam as afirmações veiculadas acerca das altas remunerações de executivos: acreditam que a remuneração é adequada. No entanto, por meio da remuneração proposta não há um reflexo em mudanças no desempenho das organizações, afirmam que o pagamento por performance não tem alcançado o objetivo previamente estabelecido. Para os autores, uma maneira de remuneração que diminui a distância de interesses de executivos e acionistas é oferecer ações da própria companhia como forma de remuneração. Ainda defendem que, ao alcançarem grandes resultados, os executivos deveriam receber grandes montantes e o inverso também: baixa performance deveria refletir penalidade.

Murphy (2011) ainda explorou questões legais e regulamentares acerca da remuneração executiva nos Estados Unidos. Em estudo qualitativo, o autor passa pelos anos 1980 que foi marcado pela aprovação de regras tributárias, normas contábeis, estabelecimento de divulgação e legislação específica para o tema. Murphy 
(2011) afirma que a regulação não exerceu efeitos significativos na relação empresa x agente. Na contramão da regulação, o mercado estabelece o episódio dos Golden parachutes plan nos anos 1980, opções nos anos 1990 e ações restritas nos anos 2000. O autor concluiu que a regulamentação da temática legou a atender apenas o legislador e deixou de lado interesses dos próprios acionistas, não contribuindo para o problema de agência.

Murphy e Jensen (2011) investigaram as causas dos problemas associados aos planos de remuneração executiva; focaram na escolha de medidas certas de desempenho, com determinação de performances limiares, metas e benchmarks e a relação com a remuneração. No mesmo estudo, investigaram o comportamento do pagamento de bônus em empresas financeiras em meio à crise mundial. Murphy e Jensen (2011) afirmam que os planos não devem ser medidos pelo desempenho apenas de um período. Para eles, deve haver intensificação do board em relação à investigação sobre earnings management, acompanhamento de volatilidade de fluxos de caixa; não oferecer pagamento de uma vez, mas com remuneração ao longo da realização de fluxos de caixa; e incrementar medidas de avaliação como ROA, EPS e ROE.

Jensen e Murphy (2012) investigaram a prática de earnings management na relação entre gerentes, membros de conselhos e analistas do mercado de capitais. Segundo os autores, esta prática é caracterizada pela tomada de decisões por parte de executivos que se alinham com determinados agentes de mercados para "produzir" resultados previamente acordados. Afirmam, ainda, que esta prática culmina em perdas para a própria companhia, além de perdas para acionistas, clientes, empregados e comunidade como um todo, além de prejudicar significativamente o funcionamento do mercado e leva à destruição de valor em longo prazo. Os autores sugerem maneiras de coibir tais atos, que consistem em: i) os executivos não devem ser premiados pelo rápido crescimento no preço das ações; ii) as empresas devem acabar com o gerenciamento de resultados e o jogo de orientação de lucros que se tornou comum entre as empresas de capital aberto e os analistas; e iii) os executivos seniores devem se comunicar com os mercados de capitais. Eles devem entender o que impulsiona o valor em sua organização e alinhar metas internas com esses drivers, não com as expectativas dos analistas.

Murphy (2012a) investigou os bônus pagos a executivos do setor financeiro norte-americano. O autor encontrou pequena evidência de que as políticas de remuneração incentivam a assunção de riscos entre os altos executivos. O autor apresenta duas regulamentações impostas pelo Poder Legislativo norte-americano, que limitava o pagamento ao alto escalão que, segundo o autor, não serviu para reduzir o risco, melhorar o pagamento ou proteger credores. $\mathrm{O}$ autor conclui que as políticas de governança corporativa apresentam uma funcionalidade maior nas empresas e contribuem para a mitigação dos problemas de agência quando comparadas à regulamentações impostas pelo Legislativo.

Murphy (2012b) sumarizou o estado da arte acerca da remuneração executiva nos Estados Unidos e em multinacionais, com avaliação da evolução da temática no último século. $\mathrm{O}$ autor aponta para os achados mais recentes em que há um fortalecimento de contratos eficientes e em habilidades gerenciais e enfraquecimento no que tange às regras de divulgação, políticas tributárias, regras contábeis e legislação em geral. O autor critica a intervenção governamental e afirma que tem sido tanto uma resposta quanto um grande fator de tendência temporal na remuneração dos executivos no fim século passado. Murphy (2012b) ainda conclui que qualquer explicação para o pagamento que ignore os fatores políticos é criticamente incompleta.

Murphy (2013) investigou a limitação imposta pela União Europeia à remuneração variável executiva de bancos daquela região. $\mathrm{O}$ autor encontrou aumento no incentivo à tomada de decisão de risco, efeito inverso ao esperado pelos reguladores. Também encontrou um aumento significativo na remuneração fixa, redução de incentivos à criação de valor, redução de competitividade entre os bancos da Europa, fatos que culminaram na redução de investimentos nos bancos e consequente redução do acesso ao capital e aumento no custo dos empréstimos.

Conyon (2014) ainda apresenta em seu estudo a remuneração executiva e as práticas de governança corporativa em empresas norte-americanas. Encontrou correlação entre a remuneração média dos executivos e o desempenho das empresas e seu tamanho. Identificou nos contratos incentivos por desempenho, principalmente o pagamento por meio de ações. Os comitês de remuneração são independentes e apresentam pequena evidência em maximizar a remuneração executiva. Também evidenciou que as empresas que contratam consultorias são influenciadas pelo comitê e, não, pela própria diretoria. 


\subsection{Divulgação obrigatória: China e Brasil exploram a temática}

Caracterizados por serem países de economia emergente e com a obrigatoriedade de divulgação da remuneração executiva, a partir dos anos 2010 as pesquisas sobre a temática ganham corpo na China e no Brasil.

Com a abertura do capital na China e divulgação das informações acerca da remuneração executiva, os estudos avançam para investigar o fenômeno no cenário chinês. A exemplo, Conyon e He (2012a) investigaram remuneração executiva e governança corporativa em companhias abertas chinesas. Os autores buscaram comparar o comportamento do mercado chinês frente ao mercado americano. Segundo os autores, os resultados foram consistentes com as prerrogativas tratadas na teoria da Agência, em que encontraram correlação positiva entre remuneração executiva e desempenho das companhias. Há uma remuneração maior com ações da própria companhia quando comparada com salário fixo. Observaram também que as empresas controladas pelo estado ou que apresentam estruturas concentradas de propriedade apresentam um pacote de remuneração e incentivos menor. Na linha da governança corporativa, os boards possuem papel importante. Alinhado a esses resultados, concluíram também que nas companhias em que há maior independência do executivo, a relação pagamento vs performance é mais significativa. Eles identificaram que nos Estados Unidos o pagamento a executivos é dezessete vezes maior que na China e concluíram que uma diferença significativa entre os dois cenários é o controle estatal sobre as companhias.

Conyon e He (2012b), também no ambiente chinês, investigaram a rotatividade de CEOs em relação ao desempenho das companhias, com vertentes voltadas ao mercado acionário e ao resultado contábil. O estudo alcançou cerca de $98 \%$ das companhias abertas da China no período de 1999 a 2006 . A troca do time do alto escalão das companhias é negativamente correlacionado com o resultado contábil, enquanto que a performance de mercado não apresentou resultados consistentes. Segundo os autores, os números contábeis apresentam uma força maior quando comparados com as informações de mercado, no que tange às escolhas de troca do time de executivos. Outro achado no estudo é que as empresas controladas pelo Estado apreciam mais as informações contábeis às de mercado, fato este que pode ter contribuído para os achados.

Conyon e He (2012c) investigaram a relação entre remuneração executiva e performance das companhias chinesas e se as práticas de governança corporativa impactam na remuneração e incentivos pagos aos executivos. Os autores identificaram correlação positiva entre pagamento a executivos com desempenho econômico. Também encontraram correlação positiva entre as políticas de pagamentos e o desempenho e que os pagamentos em ações sofrem influência da estrutura de governança e de capital.

No ano seguinte, Conyon e He (2013) continuaram com a parceria e estudam a relação entre remuneração executiva e fraudes corporativas na China. Encontraram uma significativa correlação negativa entre remuneração e fraudes corporativas para a amostra estudada, que compreendeu o período de 2005 a 2010. Os achados corroboram a hipótese em que há penalização de CEOs no caso de identificação de fraudes, reduzindo seus vencimentos. Os autores identificaram que em empresas em que há indícios de fraudes, a remuneração é menor. Isto ocorre principalmente em empresas sem o controle do Estado e em companhias em expansão. Segundo os achados, os mecanismos de governança ali adotados contribuem para mitigar fraudes.

Também Cordeiro, He, Canyon e Shaw (2013a) investigaram o comportamento dos contratos de remuneração de executivos chineses entre os anos de 2000 e 2010. Os autores iniciaram os estudos assumindo premissas como a i) de que a performance seria fator determinante nos contratos de remuneração; ii) força gerencial e influência resultariam em uma separação entre pagamento e performance; e iii) haveria reconhecimento por uma performance positiva, mas de que não haveria penalização por uma gestão pouco eficiente. Encontraram resultados distintos entre a remuneração executiva e resultado contábil alcançado: quando há um resultado significativo, como por exemplo, acima do setor ou acima da concorrência, há um grande reconhecimento dos gestores e premiação. Quando ocorre o inverso, há penalização para os gestores, incorrendo em alguns casos no desligamento. Não encontraram relação entre este cenário e a estrutura de propriedade ou, até mesmo, com práticas internas de governança corporativa. 
Os mesmos pesquisadores desenvolveram estudo no cenário chinês em que compararam o desempenho contábil versus o desempenho no mercado acionário como métricas para a remuneração de executivos entre os anos de 2001 e 2007. Os autores identificaram que o resultado contábil apresenta maior peso em relação ao desempenho de mercado como determinante dos contratos de remuneração executiva. Também encontraram indícios de que nas empresas controladas pelo Estado há maior confiança na informação contábil à oferecida pelo mercado. Por fim concluíram que, em empresas em que há melhor estrutura de governança, a informação de mercado apresenta-se como determinante para o desenho de contratos de remuneração executiva (Cordeiro, He, Canyon \& Shaw, 2013b).

No cenário brasileiro, os estudos são retomados nos anos 2010, com divulgação da remuneração executiva obrigatória a partir de 2009. Destaque para Silva e Chien (2013), que analisaram se as empresas brasileiras que melhor remuneram seus executivos apresentam maior valor de mercado e melhor desempenho operacional; não encontraram relação significativa entre remuneração executiva, valor e desempenho da empresa. Eles utilizaram regressão linear múltipla estimada pelo Método dos Momentos Generalizados Sistêmicos para controlar a endogeneidade.

Beuren, Silva e Mazzioni (2014) analisaram se a remuneração dos executivos está correlacionada com o tamanho e o desempenho das empresas brasileiras de capital aberto. Os resultados mostram que a remuneração dos executivos é negativa, significativamente correlacionada com o tamanho da empresa e, positivamente, com os indicadores de mercado. Contrariando as expectativas, os testes estatísticos aplicados não evidenciaram correlação entre a remuneração dos executivos e os indicadores de desempenho financeiro. Eles utilizaram estatística descritiva, teste de Normalidade, Correlação Canônica, teste Não Paramétrico de Mann-Whitney e correlação de Spearman e concluíram que há relação negativa entre o tamanho da empresa e a remuneração dos executivos e que a remuneração dos executivos está associada apenas ao desempenho de mercado das empresas.

Beuren e Silva (2015) elaboraram estudo com o objetivo de verificar a evolução da evidenciação da remuneração variável de executivos nas demonstrações financeiras das maiores empresas de capital aberto no Brasil. Lançaram mão de um estudo descritivo com abordagem qualitativa e concluíram que, com a obrigatoriedade da publicação de remuneração imposta pela CVM, houve um incremento do disclosure destas informações a partir de 2009, data de início de vigência da norma.

Tinoco, Rossi e Portugal (2015) analisaram a composição da remuneração dos executivos das quatro companhias privadas e estatais do setor elétrico com maior Ativo total negociadas na BM\&FBOVESPA, totalizando uma amostra de oito entidades. As diferenças encontradas estão em uma proporção maior de remuneração aos executivos por meio de remuneração fixa nas empresas de controle estatal, enquanto nas companhias de controle privado observa-se um maior equilíbrio. Além disso, as companhias de controle privado remuneram um valor maior do que as companhias de controle estatal. Apesar de na teoria os objetivos das empresas privadas e das empresas estatais serem diferentes, tais características não se manifestam de maneira relevante na composição das remunerações, sendo grande parte composta por remuneração fixa, benefícios e bônus (PLR) e apenas uma companhia privada, realizando remuneração por meio de ações.

Machado e Beuren (2015) verificaram como a política de remuneração de executivos, nas perspectivas de nível e estrutura, conforme a proposição de Murphy (1999), tem sido praticada por empresas industriais brasileiras, estadunidenses e inglesas no período de 2007 a 2010. A remuneração dos executivos estadunidenses é quase três vezes maior do que a dos executivos brasileiros e ingleses. Quanto à estrutura de remuneração, também não se constatou semelhanças; concluíram que a política de remuneração de executivos praticada nos três cenários não apresenta semelhanças nas perspectivas de nível e estrutura evidenciadas. 
Fernandes e Mazzioni (2015) investigaram a existência de correlação entre as medidas de desempenho em empresas financeiras brasileiras de capital aberto e a remuneração dos seus executivos. As análises das diversas correlações canônicas apontaram resultados mistos, que não permitem uma indicação consistente sobre a existência de correlação significativa entre a remuneração total dos executivos e o desempenho das empresas investigadas. Contudo, as amostras envolvendo empresas que utilizam a remuneração variável tendem a apresentar correlações positivamente significativas com as variáveis de desempenho utilizadas.

Kaveski, Vogt, Degenhart, Hein e Scarpin (2015) analisaram os fatores que determinam a remuneração baseada em ações dos diretores das empresas listadas na BM\&FBOVESPA. Os resultados apontaram que quanto maior for a eficiência da empresa em gerar lucros a partir de seus ativos e maior for sua receita total, menor será a remuneração baseada em ações dos diretores. Já quanto maior for a valorização da empresa perante o mercado, maior será a remuneração baseada em ações dos diretores.

\section{Metodologia}

Entendemos que o estudo tem sua ontologia classificada sob a posição filosófica do realismo e posição epistemológica sob o objetivismo em um paradigma funcionalista; tem caráter descritivo e é do tipo bibliométrico.

A pesquisa foi elaborada com buscas de palavras-chave, por meio da ferramenta EndNote ${ }^{\text {th }}$ e o Scientific Periodicals Electronic Library (SPELL), mantido no Brasil pela Associação Nacional de Pós-Graduação e Pesquisa em Administração (Anpad), sendo: i) Executive Compensation; ii) CEO Compensation; iii) Company performance combinada com a palavra compensation e os termos correspondentes em português na base brasileira.

Em um segundo momento, foram explorados os perfis dos pesquisadores junto ao website researchgate.net. Os artigos foram obtidos por meio das bibliotecas oferecidas pela Universidade de São Paulo, Scopus e Web of Science. Buscamos artigos de todos os tempos e consideramos como marco inicial a pesquisa de Jensen e Murphy (1990) até 2016. A data de corte foi 31 de agosto de 2016.

Com os artigos em mãos procedemos com a leitura dos resumos e elegemos os artigos que abordavam a temática. Esta revisão nos serviu de base para a composição do referencial acima. Também compusemos a lista de referencial teórico e submetemos à análise estatística descritiva com o software livre BibExcel. Os dados foram obtidos a partir do acesso a cada um dos artigos e, simultaneamente, organizados em um instrumento no formato de tabela, com os seguintes campos: autores de 1 a 5, título, meio de publicação e ano.

\section{Resultados}

Identificamos 154 artigos a partir das palavras-chave selecionadas e, após a leitura do resumo, foram excluídos 21 trabalhos, o que compôs uma amostra de 133 artigos para análise. Encontramos 10 trabalhos que precederam a pesquisa de Jensen e Murphy (1990). Durante os anos 1990, foram publicadas 25 pesquisas, 39 durante os anos 2000 e aumento expressivo nesta última década iniciada em $2010 \mathrm{com}$ 59 publicações, conforme descrevemos no Gráfico 1: 


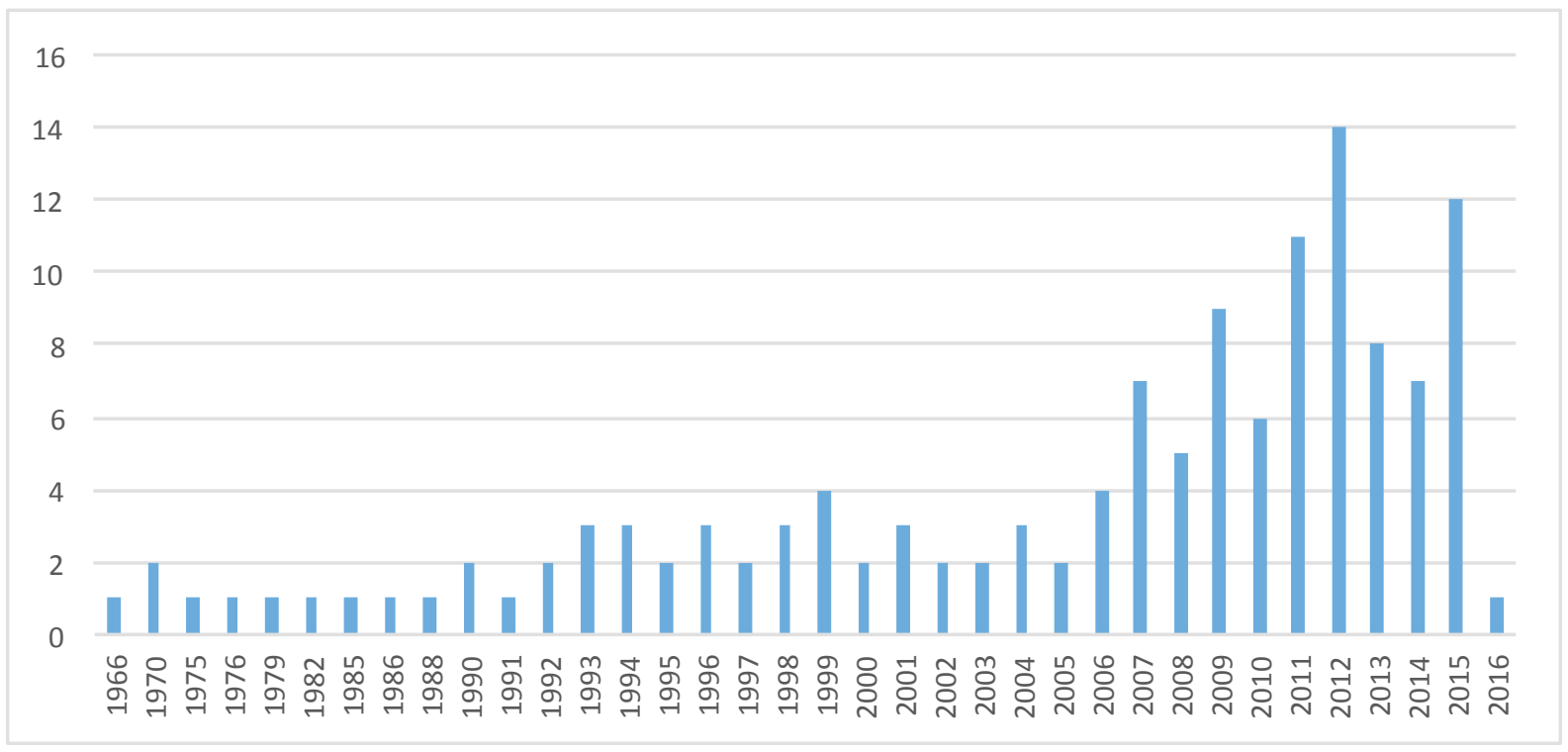

Gráfico 1. Publicações anuais

Fonte: os autores.

Os meios de divulgação das pesquisas foram classificados entre congresso, livro, periódico ou tese. Foram encontrados em congressos 13 trabalhos, 55 livros dos quais 6 publicados antes da pesquisa de Jensen e Murphy (1990) e 53 artigos publicados em periódicos e 12 teses, como demonstrado no Gráfico 2 abaixo:

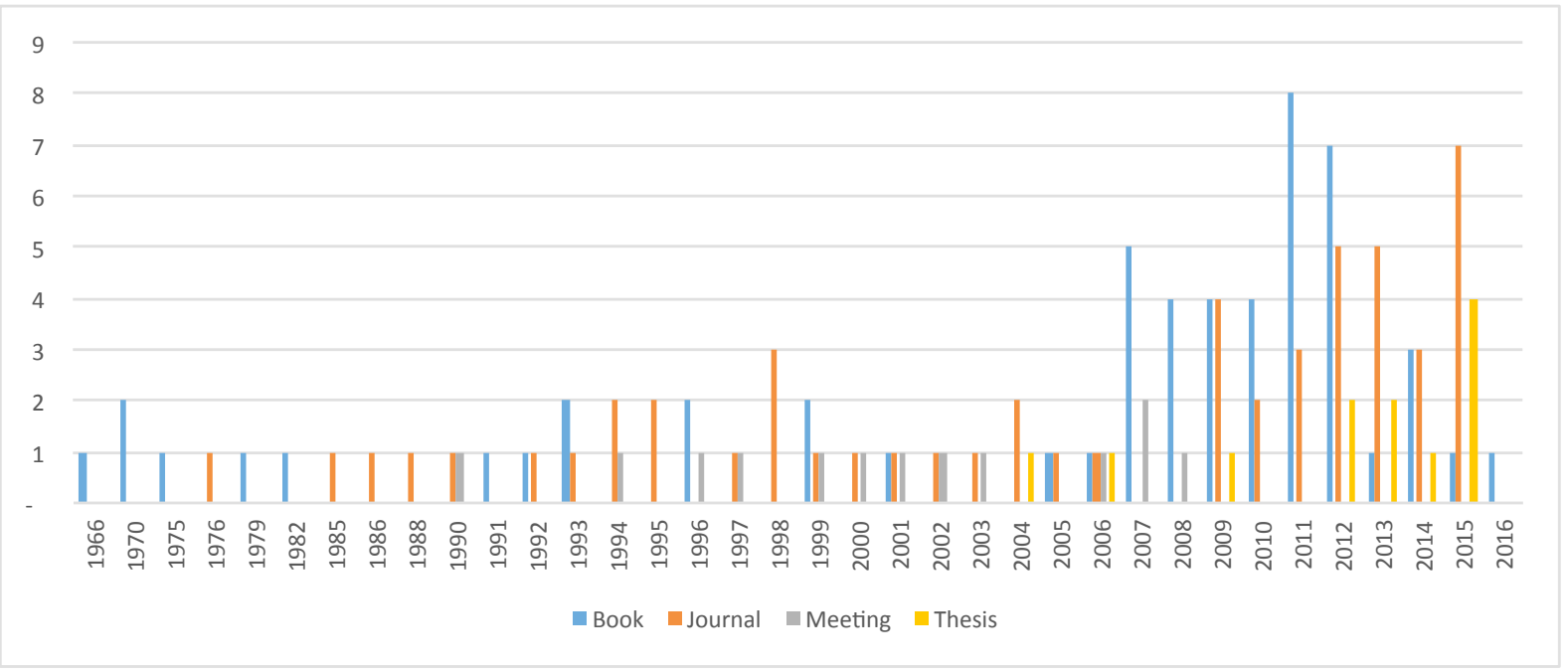

Gráfico 2. Divulgação

Fonte: os autores.

As pesquisas, em sua maioria, foram feitas em duplas (55) ou individualmente (51), com trabalhos escritos em trio apresentando frequência de 23. Encontramos 163 autores diferentes dentre os quais destacamos o professor Kevin Murphy, com 23 publicações, e o professor Martin Conyon, com 22 trabalhos. Seus principais parceiros são os professores Michael Jensen (7) e He (8), respectivamente. He destaca-se pelas pesquisas no cenário chinês e no Brasil - destaque para a prof. ${ }^{a}$ Beuren, que participou como coautora de 4 trabalhos: 


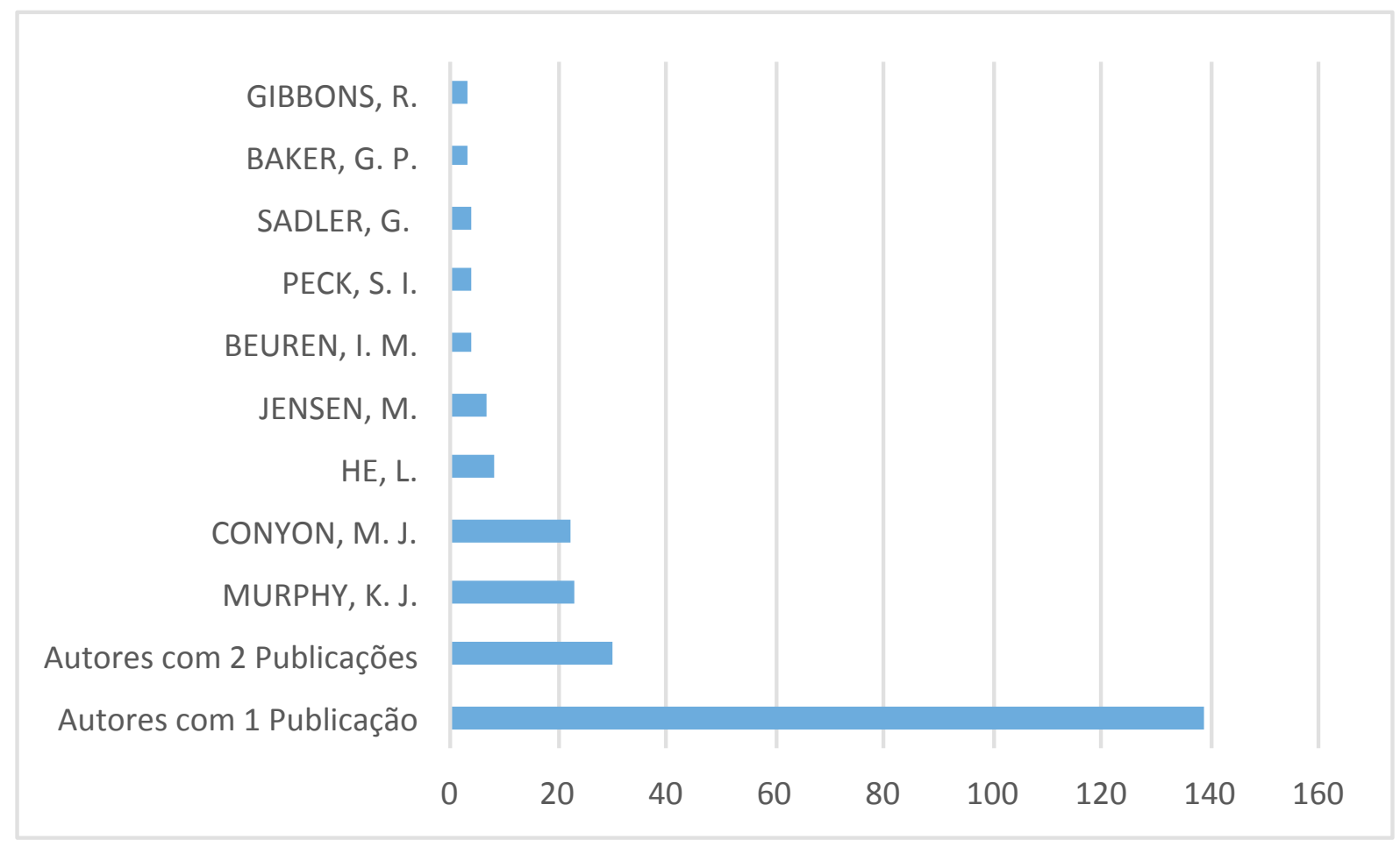

\section{Gráfico 3. Autores}

Fonte: os autores.

Também encontramos o maior número de trabalhos que investigaram o cenário norte-americano (27), seguido pelo Reino Unido (25), Brasil (11) e China (10). Destaque para as publicações a partir dos anos 2000, com franco crescimento para as investigações na China e Brasil. Nesta classificação, excluímos os livros, pois têm características teóricas e pouco empírico.

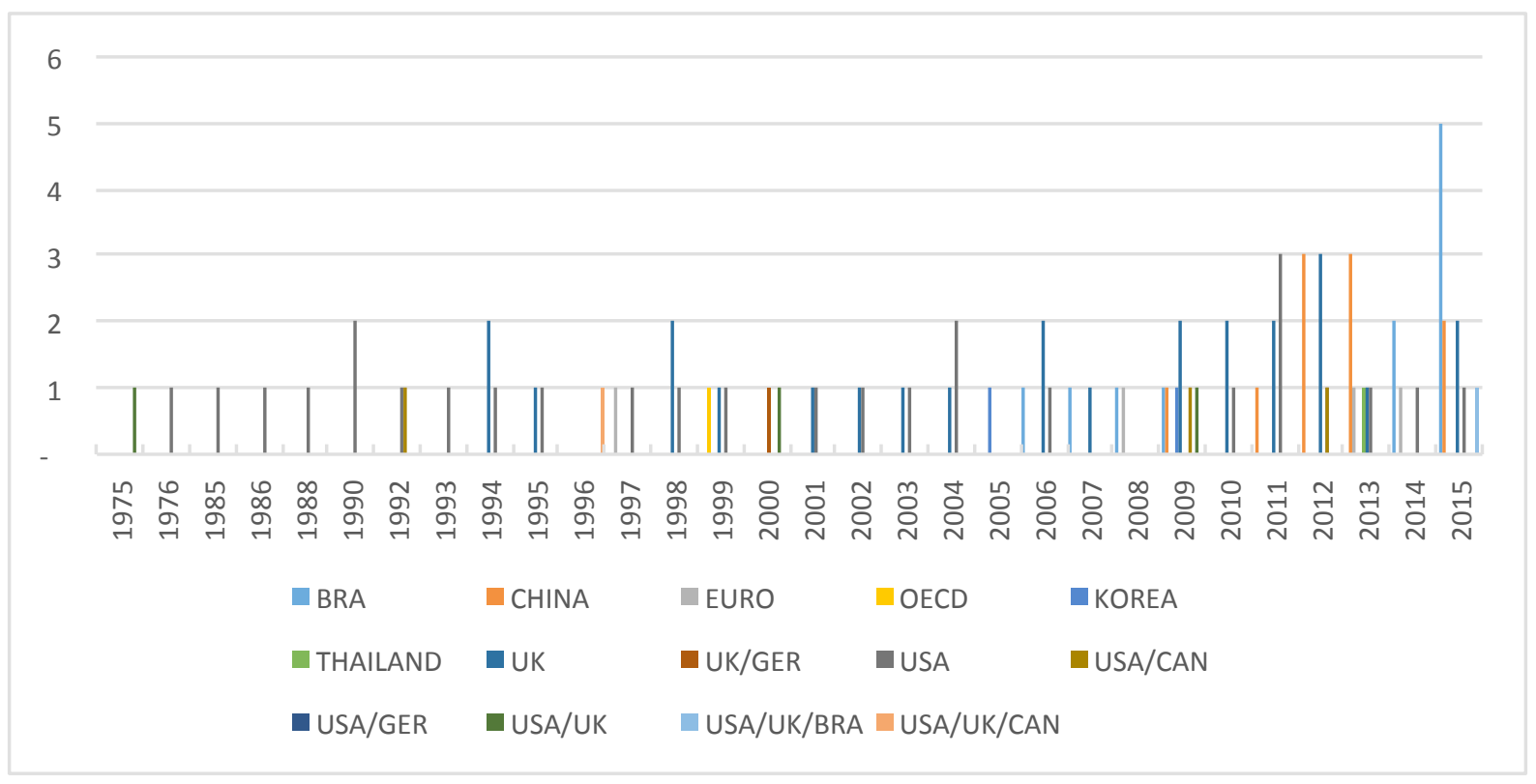

\section{Gráfico 4. Cenários}

Fonte: os autores. 
Quando alinhamos os principais autores e cenários, notamos a concentração dos estudos de Murphy em empresas norte-americanas, enquanto Conyon permeia os cenários britânico, norte-americano e encaminha-se para o chinês, principalmente em parceria com He:

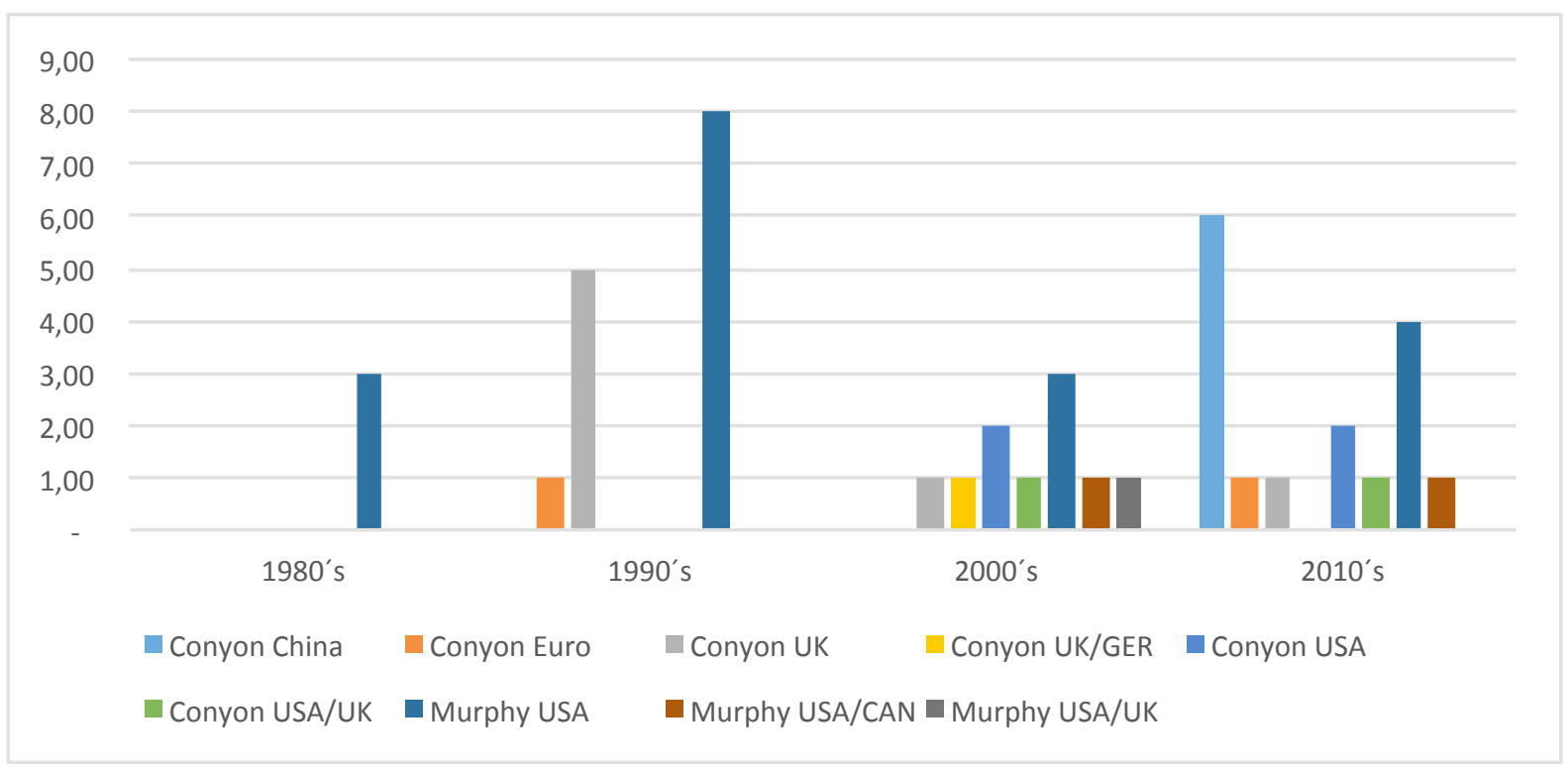

Gráfico 5. Autores e cenários

Fonte: os autores.

Conyon demonstra maior abertura para a investigação da temática em cenários diversos: iniciou seus estudos no Reino Unido, caminhou para um comparativo entre os cenários norte-americano e britânico, em parceria com o próprio Murphy, investiga também em outros países da comunidade europeia e, na última década, expande seus estudos para o cenário chinês. Enquanto Murphy concentra seus esforços no cenário americano, criticando fortemente a remuneração, os modelos impostos pelo governo por meio de regulações, questiona a prática: demonstra ser ícone sobre a temática. Trava algumas pesquisas comparando o cenário norte-americano com o canadense.

Dentro da temática "remuneração executiva", identificamos áreas de concentração dos estudos, dentre as quais destacamos: i) remuneração executiva $v s$ retorno; ii) remuneração, governança corporativa e ambientes regulatórios; iii) revisões de literatura; iv) remuneração $v s$ consultorias; v) críticas às metodologias empregadas; vi) comparativos e ; vii) determinantes de remuneração. Ao empregarmos esta classificação, encontramos a distribuição a seguir: 


\section{Frequência}

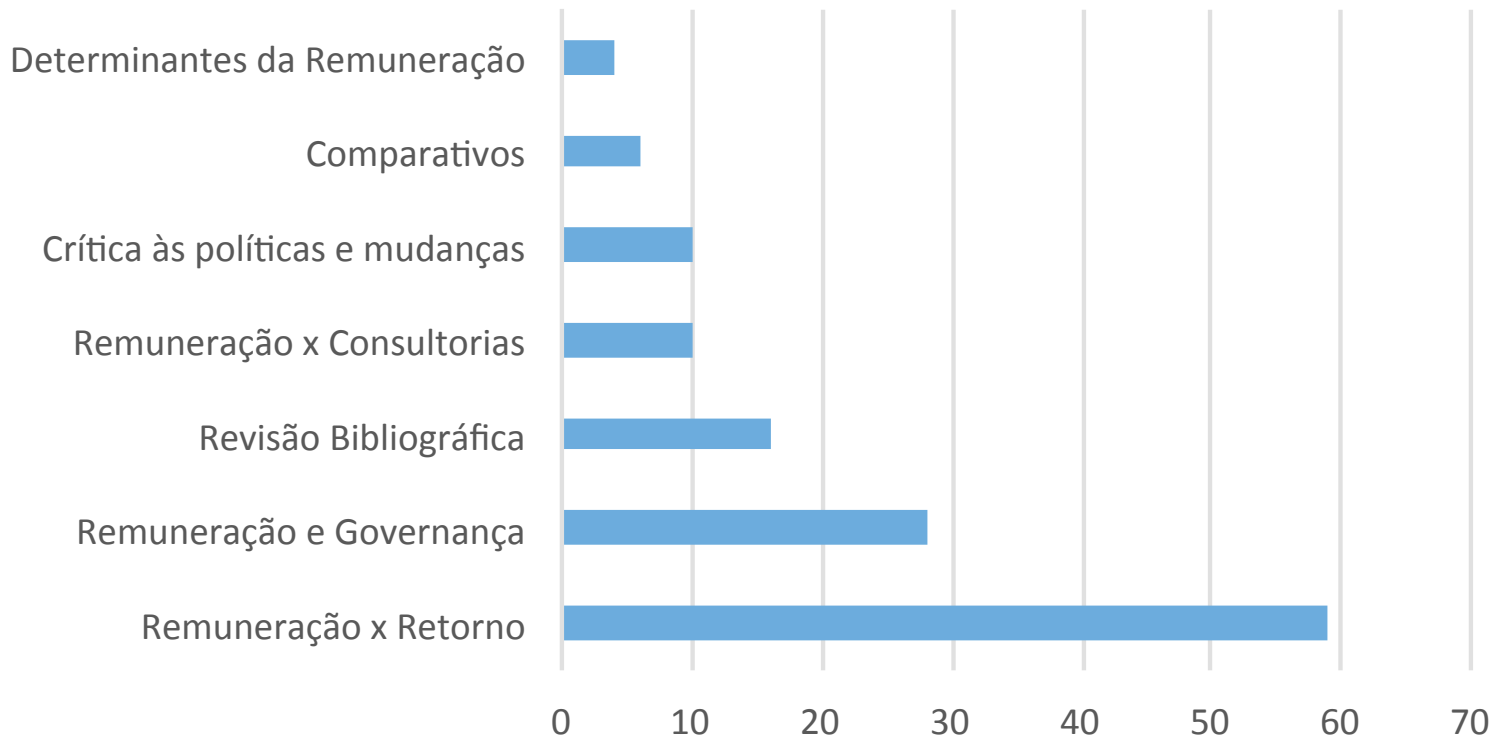

Gráfico 6. Temáticas

Fonte: os autores.

\section{Conclusões}

Neste artigo cumprimos com o objetivo de sumarizar o estado da arte da temática Remuneração Executiva e Performance Empresarial e assim prover o contexto da pesquisa nesta área. Remuneração Executiva está envolvida em questões cotidianas e sempre é questionada quando de eventos econômicos ou mesmo no ambiente político e legislativo. As discussões em volta desta temática sempre questionam os contratos eficientes e os coeficientes de remuneração e influência do board de executivos. Em alguns momentos, são deixados de lado questões, como nível de disclosure, políticas tributárias e regras contábeis, legislação em geral e, até mesmo, o clima político.

Constatamos que com o franco crescimento dos pagamentos por stock options, com início nos anos 1990, muitos estudos focaram seus esforços na criação de modelos com metodologias de cross-sections e séries temporais visando encontrar uma relação entre remuneração e retorno, principalmente nos cenários norte-americano e britânico. No entanto, grande parte destes estudos não levaram em consideração fatores relevantes como questões políticas e regulatórias.

Nossos achados contribuem para traçarmos uma linha do tempo desta temática em que pudemos observar que, na década de 1990, houve o surgimento e desenvolvimento das pesquisas com forte método quantitativo em que os pesquisadores buscavam encontrar esta relação entre remuneração e retorno. Nos anos 2000, surgem trabalhos que questionam as formas de remuneração e inserem nos modelos, variáveis antes não observadas, como aspectos de governança corporativa, políticas locais, regulação e normas contábeis. Estes achados encontram-se alinhados com os resultados da pesquisa de Murphy (2013). Na última década, notamos que os estudos deixam de ser concentrados nos cenários norte-americano e britânico e começam a se desenvolver na China e em economias emergentes, como o Brasil. 
Identificamos dois grandes autores, Kevin M. Murphy (University of Southern California) e Martin J. Conyon (University of Pennsylvania). Não podemos deixar de mencionar o prof. Michael C. Jensen (Harvard University), que participou do estudo que marcou a discussão do problema de agência (Jensen \& Meckling, 1976). Murphy desenvolve pesquisas sobre a temática a partir dos anos 1980, no cenário norte-americano, período que também marca o início dos estudos do prof. Conyon, porém, no cenário britânico. Também destacamos o crescimento das pesquisas na China em parcerias entre os professores Conyon e He.

Por fim, entendemos que as pesquisas sobre remuneração executiva se tornam ao mesmo tempo controversas e interessantes pelo fato de existirem variáveis que impactam diretamente os resultados empíricos, tais como contratos eficientes, capacidades gerenciais e questões políticas e de regulação, as quais interagem entre si. Desse modo, acreditamos que os achados aqui trazidos contribuirão para o desenvolvimento de novas pesquisas, de caráter empírico, principalmente em países em que a temática está em franco desenvolvimento ou ainda em regiões em que surge o interesse sobre o assunto, com o incremento destas variáveis para contribuir com o entendimento do problema de agência.

\section{Referências}

Abowd, J. M.; Kaplan, D. S. (1999). Executive compensation: six questions that need. DOI: http://dx.doi. org/10.3386/w7124

Alcouffe, A.; Alcouffe, C. (2000). Executive compensation: setting practices in France. Long Range Planning 33, pp. 527-543. DOI: http://dx.doi.org/10.1016/S0024-6301(00)00053-4

Araújo, C. A. (2006). Bibliometria: evolução histórica e questões atuais. Em Questão 12(1); pp. 11-32.

Araujo, J. A. O.; Parisi, C.; Silva, A. F.; Nakamura, W. T. (2014). Remuneração de executivos e desempenho das companhias abertas brasileiras: uma visão empírica após a publicação da Instrução Normativa CVM 480. Revista Brasileira de Contabilidade 209; pp. 69-83.

Baker, G. P.; Jensen, M. C.; Murphy, K. J. (1988). Compensation and incentives: practive vs theory. The Journal of Finance 42(3); pp. 88-102. DOI: http://dx.doi.org/10.1111/j.1540-6261.1988.tb04593.x

Barkema, H. G.; Gomez-Mejia, L. R. (1998). Managerial compensation and firm performance: A general research framework. Academy of Management Journal, Briarcliff Manor, 41(2), pp. 135-146. DOI: http://dx.doi.org/10.2307/257098

Beuren, I. M.; Silva, J. O. (2015). Evidenciação da remuneração variável dos executivos nas maiores empresas brasileiras listadas na BM\&F Bovespa. Enfoque Reflexão Contábil 34(3), pp. 95-124. DOI: http://dx.doi.org/10.4025/enfoque.v34i3.26154

Beuren, I. M.; Silva, M. Z.; Mazzioni, S. (2014). Remuneração dos executivos versus desempenho das empresas. Revista de Administração FACES Journal 13(2), pp. 8-25. DOI: http://sci-hub.cc/10.21714/1984-6975FACES2014V13N2ART1556

Brunello, G.; Graziami, C.; Parigi, B.M. (2001). Executive compensation and firm performance in Italy. International Journal of Industrial Organization 1(1), pp. 133-161. DOI: http://dx.doi.org/10.1016/ S0167-7187(99)00026-0

Camargos, M. A.; Helal, D. H.; Boas, A. P. (2007). Análise empírica da relação entre a remuneração de executivos e o desempenho financeiro de empresas brasileiras. Encontro Nacional De Engenharia De Produção, Rio de Janeiro, RJ, Brasil, 28.

Clarke, R. N.; Conyon, M. J.; Peck, S. I. (1998). Corporate governance and directors' remuneration: views from the top. Business Strategy Review 9(4), pp. 21-30. DOI: http://dx.doi.org/10.1111/14678616.00079 
Conyon, M. J. (1994). Corporate governance changes in UK companies between 1988 and 1993. Corporate Governance: An International Review 2(2), pp. 87-99. DOI: 10.1111/j.1467-8683.1994.tb00060.x

Conyon, M. J. (1997). Corporate governance and executive compensation. International Journal of Industrial Organization 15(4), pp. 493-509. DOI: https://doi.org/10.1016/S0167-7187(96)01032-6

Conyon, M. J. (2011). Executive compensation consultants and CEO pay. Vanderbit Law Review, 64(2), pp. 399-428.

Conyon, M. J.; Core, J. E.; Guay, W. R. (2009). Are U.S. CEOs paid more than U.K. CEOs? Inferences from risk-adjusted pay. Review of Financial Studies 24, pp. 402-438. DOI: http://dx.doi.org/10.1093/rfs/ hhq112

Conyon, M. J.; Gregg, P. (1994). Pay at the top: a study of the sensitivity of top director remuneration to company specific shocks. National Institute Economic Review 149, pp. 83-92. DOI: https://doi. org/10.1177/002795019414900107

Conyon, M. J.; Gregg, P.; Machin, S. (1995). Taking care of business: executive compensation in the United Kingdon. The Economic Journal 105(430), pp. 704-714. DOI: http://dx.doi. org/10.1080/13619469708581456

Conyon, M. J.; He, L. (2004). Compensation committees and CEO compensation incentives in US entrepreneurial firms. Journal of Management Accounting Research 16(1), pp. 35-56. DOI: http://dx.doi. org/10.2308/jmar.2004.16.1.35

Conyon, M. J.; He, L. (2012a.) Executive compensation and corporate finance in China. Journal of Corporate Finance 18 (2), pp. 1-51. DOI: http://dx.doi.org/10.1016/j.jcorpfin.2011.04.006

Conyon, M. J.; He, L. (2012b). CEO turnover in China: The role of market-based and accounting performance measures. European Journal of Finance 18(7), pp. 657-680. DOI: http://dx.doi.org/10.1080 /1351847X.2012.676559

Conyon, M. J.; He, L. (2012c). CEO compensation and corporate governance in China. Corporate Governance an International Review 20(6), pp. 575-592. DOI: http://dx.doi.org/10.1016/j.jcorpfin.2011.04.006

Conyon, M. J.; He, L. (2013). Executive compensation and corporate fraud in China. Journal of Business Ethics 112(2), pp. 187-201. DOI: http://dx.doi.org/10.1007/s10551-014-2390-6

Conyon, M. J.; (2014). Executive compensation and board governance in US firms. The Economic Journal 124(574), pp. 60-89. doi: 10.1111/ecoj.12120

Conyon, M. J.; Leech, D. (1994). Top pay, company performance and corporate governance. Oxford Bulletin of Economics and Statistics 56(3), pp. 229-247. DOI: http://dx.doi.org/10.1111/j.1468-0084.1994. mp56003001.x

Conyon, M. J.; Murphy, K. J. (2000). The prince and the pauper? CEO pay in the United States and United Kingdom. The Economic Journal 110(467), pp. 640-671. DOI: http://dx.doi.org/10.1111/14680297.00577

Conyon, M. J.; Peck, S. I. (1998). Board control, remuneration committees and top management compensation. The Academy of Management Journal 41(2), pp. 146-157. DOI: http://dx.doi. org/10.2307/257099

Conyon, M. J.; Peck, S. I.; Sadler, G. V. (2009). Compensation consultants and executive pay: Evidence from the United States and the United Kingdom. Academy Management Perspectives 23(1), pp 4355. DOI: http://dx.doi.org/10.5465/AMP.2009.37008002

Conyon, M. J.; Sadler, G. (2001). Executive pay, tournaments and corporate performance in UK firms. International Journal of Management Reviews 3(2); pp. 141-168. doi: 10.1111/1468-2370.00060 
Conyon, M. J.; Sadler, G. (2010). Shareholder voting and directors' remuneration report legislation: say on pay in the UK. Corporate Governance an Internacional Review 18(4), pp. 296-312. DOI: http:// dx.doi.org/10.1111/j.1467-8683.2010.00802.x

Conyon, M. J.; Schwalbach, J. (2000). European differences in executive pay and corporate governance. In Gabler Verlag, Wiesbaden. Horst Albach (Ed.). Corporate Governance: ZfB-Ergänzungshefte (Vol. 1, pp. 97-114). Wiesbaden: ZfB-Ergänzungshefte

Copeland, T. E.; Weston, J.F.; Shastri, K. (2007). Financial theory and corporate policy. 4th ed. London: Pearson.

Cordeiro, J.; He, L.; Conyon, M. J.; Shaw, T. (2013a). Chinese executive compensation: the role of asymmetric performance benchmarks. The European Journal of Finance 19(6); pp. 484-505. DOI: http:// dx.doi.org/10.1080/1351847X.2013.769892

Cordeiro, J.; He, L.; Conyon, M. J.; Shaw, T. (2013b). Informativeness of performance measures and Chinese executive compensation. Asia Pacific Journal of Management 30 (4), pp. 1031-1058. DOI: http:// dx.doi.org/10.1007/s10490-013-9353-9

Dial, J.; Murphy, K. J. (1995). Incentives, downsizing and value creation at general dynamics. Journal of Financial Economics 37(3), pp. 261-314. DOI: http://dx.doi.org/10.1016/0304-405X(94)00803-9

El Akremi, A.; Roussel, P.; Trepo, G. (2001). CEO compensation strategies: consequences on the structure and management of executive pay. Working paper, HEC Paris, $\mathrm{n}^{\circ} .741$.

Elston, J. A.; Goldberg, L. G. (2003). Executive compensation and agency cost in Germany. Journal of Banking \& Finance 27, pp. 1391-1410. DOI: http://dx.doi.org/10.1016/S0378-4266(02)00274-1

Fama, E. F. (1980). Agency problems and the theory of the firm. Journal of Political Economy 88(2), pp. 288-307. DOI: https://doi.org/10.1086/260866

Fernandes, F. C.; Mazzioni, S. (2015). A Correlação entre a Remuneração dos Executivos e o Desempenho de Empresas Brasileiras do Setor Financeiro. Contabilidade Vista \& Revista 26(2), pp. 41-64.

Firth M., Tam M., Tang, M (1999). The determinants of top management pay. The International Journal of Management Science 3(2), pp. 617-635. DOI: http://dx.doi.org/10.1016/S0305-0483(99)00021-3

Funchal, J. A.; Terra, P. R. S. (2006). Remuneração de executivos, desempenho econômico e governança corporativa: um estudo empírico em empresas latino-americanas. Encontro Nacional de Pesquisas em Administração. Salvador, BA, Brasil, 30.

Garen, J. E. (1994). Executive compensation and principal-agent theory. Journal of Political Economy 10 (6), pp. 522-541. DOI: http://dx.doi.org/10.1086/261967

Gibbons, R.; Murphy, K. J. (1992). Optimal incentive contracts in the presence of career concerns: theory and evidence. Journal of Political Economy 100(3); pp. 468-505. DOI: http://dx.doi.org/10.3386/w3792

Gregg, P.; Machin, S.; Szymanski, S. (1993). The disappearing relationship between directors' pay and corporate performance. British Journal of Industrial Relation 31(1). Pp. 1-9. DOI: 10.1111/j.14678543.1993.tb00377.x

Hall, B. J.; Murphy, K. J. (2003). The trouble with stock options. Journal of Economic Perspectives 17 (3), pp. 49-70. DOI: http://dx.doi.org/10.3386/w9784

Holmström, B. (1982). Moral hazard in teams. The Bell Journal of Economics 13(2), pp. 324-340. DOI: $10.2307 / 3003457$

Jensen, M.; Meckling, W. (1976). Theory of the firm: managerial behavior, agency costs and ownership structure. Journal of Financial Economics, New York 3(4), pp. 305-360. DOI: http://dx.doi. org/10.1016/0304-405X(76)90026-X 
Jensen, M.; Murphy, K. J. (1990). Performance pay and top-management incentives. Journal of Political Economy, Chicago 98(2), pp. 225-264. DOI: http://dx.doi.org/10.1086/261677

Jensen, M.; Murphy, K. J. (2010). CEO incentives: it's not how much you pay, but how. Journal of Applied Corporate Finance 22(1), pp. 64-76. DOI: http://dx.doi.org/10.1111/j.1745-6622.2010.00262.x

Jensen, M.; Murphy, K. J. (2012). The earnings management game: it's time to stop it [Working Paper n. 12-004]. Harvard Business School NOM Unit, Boston, United States of America. DOI: http://dx.doi. org/10.2139/ssrn.1894304

Jensen, M.; Murphy, K. J.; Wruck, E. G. (2004). Where we've been, how we got to here, what are the problems, and how to fix them [Working Paper n. 44 / WEP. 2-117]. European Corporate Governance Institute, Bruxelas, Belgium.

Kato, T.; Kim, W.; Lee, J. H. (2005). Executive compensation, firm performance, and chaebols in Korea: evidence from new panel data. Discussion Paper Series. Bonn, IZA DP, n. 1783. DOI: http://dx.doi. org/10.1016/j.pacfin.2006.03.004

Kaveski, I. D. S. S.; Vogt, M.; Degenhart, L.; Hein, N.; Scarpin, J. E. (2015). Fatores determinantes da remuneração baseada em ações de empresas brasileiras. Revista de Administração da Unimep 13(2), pp. 100-116. DOI: http://dx.doi.org/10.15600/1679-5350/rau.v13n2p100-116

Krauter, E; Sousa, A. F. (2013). A Relação entre a Remuneração de Executivos e o Desempenho Financeiro das Empresas. Revista de Educação e Pesquisa em Contabilidade 7(3), pp. 259-273. DOI: http:// dx.doi.org/10.17524/repec.v7i3.988

Leonard, J. S. (1990). Executive pay and firm performance. Industrial \& Labor Relations Review, Cornell, 43 (3), pp. 13-S-29-S. DOI: http://dx.doi.org/10.2307/2523569

Machado, D. G.; Beuren, I. M. (2015). Política de Remuneração de Executivos: um Estudo em Empresas Industriais Brasileiras, Estadunidenses e Inglesas. Gestão \& Regionalidade 31(92), pp. 4-24. DOI: http://dx.doi.org/10.13037/gr.vol31n92.2088

Main, B. (1992). Top executive pay and company performance. Edinburgh, University of Edinburgh.

Main, B.; Johnston, J. (I993). Remuneration committees and corporate governance. Accounting and Business Research 23(1), pp. 35-62. DOI: http://sci-hub.cc/10.1080/00014788.1993.9729903

McKnight, P. (1996). An explanation of top executive pay: a UK study. British Journal of Industrial Relations 3(1), pp. 557-566. DOI: http://dx.doi.org/10.1111/j.1467-8543.1996.tb00490.x

Miller, D. J. (1995). CEO salary increases may be rational after all: referents and contracts in CEO pay. Academy of Management Journal 38(5), pp. 1361-1385. DOI: http://dx.doi.org/10.2307/256861

Murphy, K. J. (1985). Corporate performance and managerial remuneration: an empirical analysis. Journal of Accounting and Economics 7(1), pp. 11-42. DOI: http://dx.doi.org/10.1016/0165-4101(85)90026-6

Murphy, K. J. (1998). Executive compensation. SSRN Electronic Journal, v. 3b.

Murphy, K. J. (2011). The politics of pay: a legislative history of executive compensation [Working Paper n. FBE 01.11]. SSRN Electronic Journal, South Los Angeles, United States of America. DOI: http:// dx.doi.org/10.2139/ssrn

Murphy, K. J. (2012a). Pay, politics and the financial crisis. In: Blinder, A.; Lo, A.; Solow, R. Rethinking the Financial Crisis, New York: Russell Sage Foundation.

Murphy, K. J. (2012b). Executive compensation: where we are, and how we got there. In: Constantinides, G.; Harris, M.; Stulz, R. Handbook of the Economics of Finance, North Holland: Elsevier Science. doi: $10.2139 /$ ssrn.2041679 
Murphy, K. J. (2013). Regulating banking bonuses in the European Union: a case study in unintended consequences. European Financial Management 19(4), pp. 631-657. DOI: http://dx.doi.org/10.1111/ j.1468-036X.2013.12024.x

Murphy, K. J.; Jensen, M. C. (2011). CEO bônus plan: and how to fix them [Working Paper n. 12-022 / FBE 02-11]. SSRN Electronic Journal, South Los Angeles, United States of America. DOI: http:// dx.doi.org/10.2139/ssrn

Murphy, K. J.; Sandino, T. (2009). Executive pay and "independet" compensation consultants. Journal of Accounting and Economics 49(3), pp. 247-262. DOI: http://dx.doi.org/10.1.1.318.1670

Murphy, K. J.; Sandino, T. (2012). Are consultants to blame for high executive pay? SSRN Electronic Journal. DOI: http://dx.doi.org/10.2139/ssrn.2133059

Pukthuanthong, K.; Talmor, E.; Wallace, J. S. (2004). Corporate governance and theories of executive pay. Corporate Ownership \& Control 1(2), pp. 41-62. DOI: http://dx.doi.org/10.1007/s10551-015-2962-0

Quevedo-Silva, F.; Santos, E. B. A.; Brandão, M. M.; Vils, L. (2016). Estudo bibliométrico: orientações sobre sua aplicação. Revista Brasileira de Marketing 15(2), pp. 246-262. DOI: http://dx.doi.org/10.5585/ remark.v15i2.3274

Rosen, S. Contract and the Market for executives. (1990). Nobel Symposium (3542): 1-54. DOI: http:// dx.doi.org/10.3386/w3542

Silva, A. L. C.; Chien, A. C. (2013). Remuneração executiva, valor e desempenho das empresas brasileiras listadas. Revista Brasileira de Finanças 11(4), pp. 481-502.

Tinoco, P. P.; Rossi, G. A. S.; Portugal, G. T. (2015). Remuneração dos Executivos das Companhias Estatais e Privadas de Energia Elétrica com Maiores Ativos Listadas na BM\&FBOVESPA. Contabilidade, Gestão e Governança 18(3), pp. 142-161. 